NBER WORKING PAPER SERIES

FINANCING ENTREPRENEURIAL EXPERIMENTATION

\author{
Ramana Nanda \\ Matthew Rhodes-Kropf \\ Working Paper 21278 \\ http://www.nber.org/papers/w21278 \\ NATIONAL BUREAU OF ECONOMIC RESEARCH \\ 1050 Massachusetts Avenue \\ Cambridge, MA 02138 \\ June 2015
}

This paper has been written for the NBER's Book Series, Innovation Policy and the Economy, volume 16. We draw extensively on the examples used in William Kerr, Ramana Nanda and Matthew RhodesKropf (2014) and Ramana Nanda (2015) throughout this chapter. We thank Josh Lerner, Scott Stern, Navid Bazzazian and participants at the 2015 NBER Innovation Policy and Economy Conference for helpful comments. All errors are our own. The views expressed herein are those of the authors and do not necessarily reflect the views of the National Bureau of Economic Research.

NBER working papers are circulated for discussion and comment purposes. They have not been peerreviewed or been subject to the review by the NBER Board of Directors that accompanies official NBER publications.

(C) 2015 by Ramana Nanda and Matthew Rhodes-Kropf. All rights reserved. Short sections of text, not to exceed two paragraphs, may be quoted without explicit permission provided that full credit, including $(\mathcal{C}$ notice, is given to the source. 
Financing Entrepreneurial Experimentation

Ramana Nanda and Matthew Rhodes-Kropf

NBER Working Paper No. 21278

June 2015, Revised October 2015

JEL No. G24,L26,O31

\begin{abstract}
The fundamental uncertainty of new technologies at their earliest stages implies that it is virtually impossible to know the true potential of a venture without learning about its viability through a sequence of investments over time. We show how this process of experimentation can be particularly valuable in the context of entrepreneurship because most new ventures fail completely, and only a few become extremely successful. We also shed light on important costs to this process of experimentation, and demonstrate how these can fundamentally alter both the rate and direction of startup innovation across industries, regions and periods of time.
\end{abstract}

\author{
Ramana Nanda \\ Harvard Business School \\ Rock Center 317 \\ Soldiers Field \\ Boston, MA 02163 \\ and NBER \\ rnanda@hbs.edu \\ Matthew Rhodes-Kropf \\ Harvard Business School \\ Rock Center 313 \\ Soldiers Field \\ Boston, MA 02163 \\ and NBER \\ mrhodeskropf@hbs.edu
}




\section{Financing Entrepreneurial Experimentation}

\section{Introduction}

When it was founded in 1999, Google was in many ways a long-shot investment. Its founders were students, it was entering a space with many established competitors and had no clear business model. In fact, more than one venture capitalist had turned down the opportunity to invest in Google at the time. One such firm was Bessemer Ventures, whose partner David Cowan, on being asked to meet with the two Google founders working in the garage, is believed to have quipped, "Students? A new search engine? ... How can I get out of this house without going anywhere near your garage?"

Not everyone is as candid as about great deals they passed on as Bessemer Ventures, who have been so successful that they can playfully mock at their 'anti-portfolio' of investments. ${ }^{1}$ Nevertheless, the example of Google and of Bessemer Ventures frames a key challenge for policy-makers engaged in entrepreneurship: although entrepreneurship is widely acknowledged as being central to economic growth, the commercialization of the most promising ideas is not guaranteed, and depends critically on the ability of entrepreneurs to raise startup capital. The fundamental uncertainty of new technologies at their earliest stages implies that it is virtually impossible for financiers to know the true potential of a new venture. Often the only way to understand its potential is to learn about its viability through a sequence of investments over time. Investors therefore play the role of gatekeepers as they decide whether to make an initial investment to learn about the viability of a radical new idea, how to interpret intermediate results, and whether to continue or abandon their investment. Costs or constraints to this experimentation can not only impede entrepreneurship, but also fundamentally alter the trajectory of innovation in the economy by shaping which industries, regions, and time periods see the most

${ }^{1}$ see http://www.bvp.com/portfolio/antiportfolio 
radical innovations.

In this paper, we synthesize recent research on the role of finance in entrepreneurial experimentation. Our focus is on the financing of startups that commercialize new technologies. These startups form a small share of new firms each year, but are central to the process of creative destruction through their role in creating new industries (such as automobiles, semi-conductors, biotechnology or the internet) and the introduction of disruptive innovations in existing industries. ${ }^{2}$ For example, only about 1,000 of the 500,000 new startups each year in the United States receive a first round of venture capital (VC) funding, but VC-backed firms account for about half of US IPOs each year. The process of experimentation across multiple rounds of financing is particularly valuable for such ventures because most fail completely, and only a few, such as Google, become extremely successful (Robert E. Hall and Susan E. Woodward (2010)).

Experimentation allows investors learn about a venture's potential over time. Importantly, the ability to abandon investments at an intermediate point, before committing the full amount of capital, allows investors to finance an initial exploration into an idea that would not have been funded in an all-or-nothing bet. This is also good for entrepreneurs in that it allows more ideas to get an initial round of funding, but also implies that many projects are shut down early when intermediate information about their prospects is poor. Viewed from the perspective of experimentation, failure is not necessarily bad if the best projects are being selected and advanced. In fact, a large number of failed startups might even be an indication that investors are willing to finance extremely novel, radical, technologies. Nevertheless, a few thousand individuals working in a few hundred venture capital firms are largely responsible for choosing and advancing the most radical innova-

\footnotetext{
${ }^{2}$ This does not diminish the contribution of other startups to productivity growth in the economy. For example, the vast majority of startups do not commercialize new technologies, but a substantial share of productivity growth across the economy is shown to arise from the birth of more productive firms and the closure of unproductive firms rather than just through existing firms becoming more productive. Such firms (over $80 \%$ of which are in Construction, Retail and Wholesale Trade and Services) rely principally on their savings, personal loans or commercial credit to fund their operations and growth. Banks are the principal financiers for such ventures and are not the focus of this paper.
} 
tions in the US economy, and it is easy to see how financing frictions may lead investors to systematically overlook, or inefficiently shut down some extremely promising ventures. ${ }^{3}$ Our paper provides a framework for understanding this process of experimentation and the sources of financing frictions. This naturally sets up the ways in which policies towards the financing of experimentation might help alleviate financing constraints for startups engaged in innovation.

The rest of the paper is structured as follows. In Section 2, we develop a simple framework that compares an all-or-nothing investment with one where the investor can experiment and abandon the investment at an intermediate stage, to provide an intuition for the key results. Section 3 examines how the falling cost of an early experiment impact the type of entrepreneurs who are backed, and sectors that see the most innovation. We show that investors naturally gravitate to sectors where the cost of experimentation is lower, independent of the areas where there is the greatest need for innovation, or even where the supply of innovative ideas are greatest. In Section 4, we consider how the ebbs and flows of capital interact with the financing of experimentation. We show how even when the initial experiment goes well, shocks to the availability of capital can impact the ability of a firm to finance its next stage. The fluxes in capital and investors' beliefs about the availability of capital at the next round of funding can have important implications for whether investors are willing to finance an initial experiment at a given moment in time. For example, hot financial markets can amplify and even drive innovation in the real economy, as these are instances in which investors are most likely to finance an initial exploration into a novel, new technology. Section 5 examines frictions associated with abandoning investments when intermediate information is negative. Investors may want to build a reputation as being 'entrepreneur friendly', may face organizational resistance because investors have pet projects or may want to set a policy for being 'failure tolerant'.

\footnotetext{
${ }^{3}$ For example, the National Venture Capital Association reports that there were 462 active venture capital firms in the US in 2010 (Kerr, Nanda and Rhodes-Kropf (2014)).
} 
These factors have a bearing on what projects investors may start, and hence organizational and even institutional factors can drive the extent to which radical innovations are funded in certain firms or certain regions. Section 6 concludes.

\section{Why is Experimentation Important?}

Startups engaged in innovation face fundamental uncertainty associated with their prospects. A good example of the difficulty in determining how well a new venture will do comes from Kerr, Nanda and Rhodes-Kropf (2014), who study internal data from a single large and successful US venture capital firm. They look at ratings the partners at this firm gave each deal at the time of first investment and study how this score relates to the ultimate outcome of the same startups. They find that the correlation between initial scores and ultimate performance of startups was 0.1 , showing how even successful professional investors have a hard time distinguishing among the most promising startups at the earliest stages of investment. Using similar data from an angel investment group, Kerr, Lerner and Schoar (2014), find the correlation among the interest levels assigned to funded deals and their ultimate success was less than 0.1 . More generally, that fact that the majority of venture capital investments fail (nearly $60 \%$ of this VC's investments returned less than the money invested) is itself indicative of the difficulty in predicting which firms will be successful and which will fail.

In this environment of extreme uncertainty, experimentation allows investors and entrepreneurs to pursue projects that are not feasible in an all-or-nothing bet. A number of papers on venture capital have demonstrated that financiers of innovative firms want to stage their investments and learn more about the firm's potential before investing further, in order to preserve the real-option to terminate their investment (see Paul Gompers, 1995; Franchesca Cornelli and O. Yosha, 2003; Dirk Bergemann and Ulrich Hege, 2005; Z. Fluck, K Garrison and S. Myers, 2007; Dirk Bergemann, Ulrich Hege and Liang Peng, 
2008). In fact, it is standard for venture capitalists to negotiate control rights that allow the investors to fire management and/or abandon the project (see Paul Gompers and Josh Lerner (2004), William A. Sahlman (1990) and Thomas Hellmann (1998)). Even among venture backed firms that are 'successful' Thomas Hellmann and Manju Puri (2002) and Steven Kaplan, Berk Sensoy and Per Stromberg (2009) show that many end up with CEOs who are different from the founders. To help demonstrate the key idea we set up a simple

PANEL A: ALL OR NOTHING BET

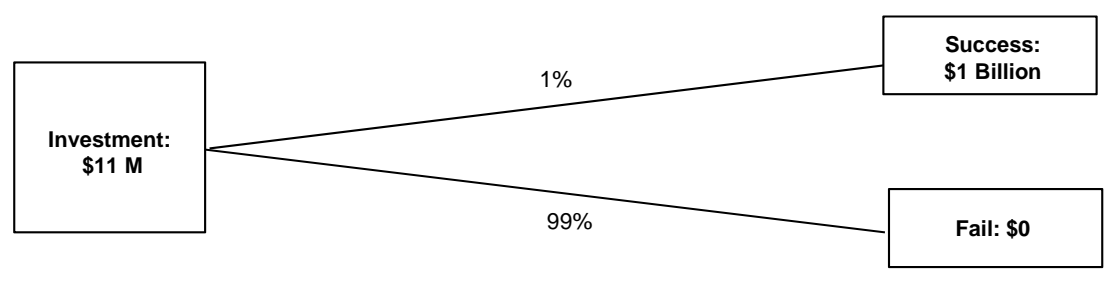

PANEL B: STAGED FINANCING

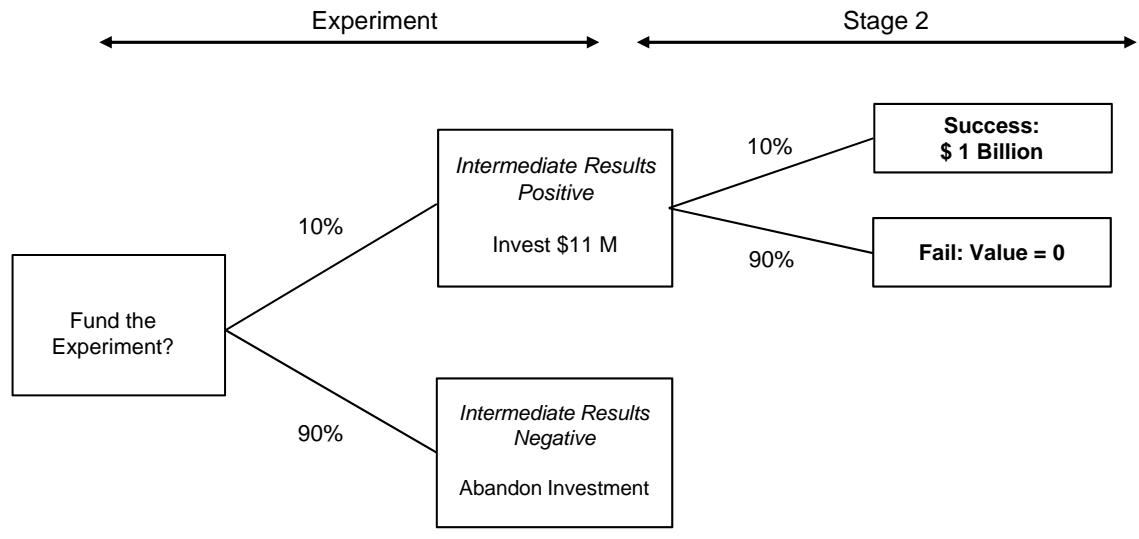

Figure 1. Investor's Decision Tree

Consider a startup that requires $\$ 11$ million to commercialize, will be worth $\$ 0$ with $99 \%$ probability, and will be worth $\$ 1$ billion (V) with $1 \%$ probability. This project will not be pursued as its expected value is negative $(-\$ 1 M)$, i.e., $\$ 11 M>0.01 * \$ 1 B$. But what if the entrepreneurs can conduct an experiment that will reveal that the project either has a $10 \%$ chance of working or a zero percent chance of working. Furthermore, assume 
this experiment will reveal the more promising news with a $10 \%$ probability. Thus, the unconditional probability of success, $1 \%$, is the same whether or not the entrepreneurs conduct the experiment. The decision tree of the investor is shown in figure 1.

The question facing the investor is whether it is worthwhile to finance the initial experiment. Intuition might suggest that since running the experiment increases the amount the investor has to pay, the experiment is not worth pursuing. However, the value in the experiment arises because it may prevent the investor from spending $\$ 11$ million at all.

The experiment can thus be thought of as an investment that pays off $\$ 89$ million with $10 \%$ probability and pays off $\$ 0$ with $90 \%$ probability (since the investor will not invest the $\$ 11$ million if the the results of the experiment are not promising). In our example, the probability that initial information is positive is $10 \%$, so that the expected value of the experiment is $10 \% * \$ 89$ million $=\$ 8.9$ million. Thus, as long as the experiment costs less than $\$ 8.9$ million, it should be run.

We see from this that even though the original investment of $\$ 11$ million was not a good idea, an investment of up to $\$ 8.9$ million followed by an investment of $\$ 11$ million if the experiment is successful is a good idea - it is positive expected value. Spending an additional $\$ 8.9$ million to learn about the viability of the project is more valuable than simply directly spending $\$ 11$ million. This is the power of experimentation. ${ }^{4}$

The value of experimentation stems from two sources. The first is the cost of the experiment. Intuitively, it is easy to see that experiments that are not expensive to run are more likely to be valuable. The second driver of the value of experimentation is the amount of information that the experiment generates. More discriminating experiments generate more information and hence make it easier for an investor to decide whether to abandon their investment or continue financing the next stage. In an extreme, an experiment might demonstrate nothing. That is, the probability of earning $\$ 1$ billion

\footnotetext{
${ }^{4}$ We emphasize that the value of experimentation is not driven by the specific numbers chosen in this example. The Appendix provides a formal model to show this.
} 
is the same no matter the experiment's outcome. Alternatively, the experiment might provide a great deal of information. In this case, the value of the startup conditional on intermediate success would be much larger than the value of the startup conditional on failure. We can think, therefore, of the difference in the value of the startup when the experiment works and when it fails, as the amount or quality of the information revealed by the experiment. This difference is larger if the experiment reveals more about what might happen in the future. Overall, we see that experimentation is very valuable in situations when relatively small dollars invested can reveal information that results either in a valuable project going forward or preventing a mistaken investment.

This simple example can be used to demonstrate the ideas that underlie recent work on entrepreneurial experimentation and finance and reveal the relevant policy implications. Given the need to experiment as a backdrop, we focus on three aspects of the financing of experimentation and the policies they imply. We will start with implications surrounding the costs of experimentation. Then we will consider how experimentation interacts with volatile financial markets and the risk a project will not be able to find financing in the future even if the intermediate information is positive. Finally, we will examine the benefits and costs surrounding investor tolerance toward early experimental failure when intermediate information is negative.

\section{The Falling Costs of Experimentation and the Change in the Financing of Entrepreneurship}

The above model makes the importance of the costs of experimentation very clear. If an early experiment can be run cheaply and reveal enough information, then a startup can be financed that otherwise could not. For example, technologies such as the internet, open source software, cloud computing, etc., have reduced the costs associated with starting a new company. This shift has led to new ways to think about entrepreneurship, such 
as the Lean Startup methodology advocated by Steve Blank and popularized by Eric Ries (2011). The crux of Lean Startup Methodology is to identify and develop a "minimal viable products" (MVP). This experimental product seeks to validate as many assumptions as possible about the viability of the final product before expending enormous effort and financial resources. The followers of this methodology frequently discuss how to make their experiments more cost effective, in large part so that they do not need to raise as much money to pursue their ideas. As shown in the Appendix, a falling cost of experimentation is particularly valuable for startups that are "long shot bets". These are startups startups with low chances of initial success but where an investor can learn a significant amount from an initial experiment.

The last two decades have seen dramatically lower costs associated with starting new firms, particularly in industries that have benefited from the emergence of the Internet, open source software, and cloud computing. Industry observers suggest that initial experiments to learn about the viability of an idea in these sectors would have cost $\$ 5$ million a decade ago, but can be conducted for under $\$ 50,000$ today. For example, Mark Andreessen, a prominent venture capital investor, notes that "In the 90s, if you wanted to build an Internet company, you needed to buy Sun servers, Cisco networking gear, Oracle databases, and EMC storage systems... and those companies would charge you a ton of money even just to get up and running. The new startups today, they don't buy any of that stuff... They're paying somewhere between 100x and 1000x [less] per unit of compute, per unit of storage, per unit of networking". Andreessen also notes that the rise of services such as Amazon's Elastic Compute Cloud (EC2) have transformed many infrastructure costs from upfront capital expenditures to subscription services that can scale with a company as it grows..$^{5}$ Each of these features has made it significantly cheaper to finance an initial exploration into the viability of a new idea. However, not all industries have been

\footnotetext{
${ }^{5}$ Douglas Macmillan, 'Andreessen: Bubble Believers Don’t Know What They're Talking About', Wall Street Journal, January 3, 2014.
} 
equally affected by the technologies that have led to a fall in the cost of experimentation. In particular, the advent of Amazon's elastic cloud compute services (EC2) lowered the cost of starting businesses in certain technology segments such as computer software and internet business. However, biotech and medical device firms were logically less impacted by cloud computing.

Michael Ewens, Ramana Nanda and Matthew Rhodes-Kropf (2015) use this idea and compare new firms funded in the 2006-2010 period to those funded in the 2002-2005 period across different industries. Consistent with the predictions of the model, they find investors are more likely to back unproven founding teams in the post period when the startup is in an industry segment that benefited from Amazon's EC2 services. In these sectors, VCs backed younger founders and fewer serial entrepreneurs - these are startups that are likely to have a lower chance of success, but where the investor can now learn a lot about the venture's 'traction' with consumers without a large upfront investment. These results suggest that the falling cost of experimentation has helped to democratize entry, particularly among young, unproven founding teams and has allowed for greater experimentation in certain sectors of the economy.

Cheeper experimentation also allows more 'audacious' and costly projects to be completed. Going back to the example in Section 2, we saw that an $\$ 8.9$ million experiment followed by an $\$ 11$ million investment had a positive expected value, but if the required investment in the second stage was any more than $\$ 11$ million then the project would not be started. If the cost of the initial experiment dropped to say $\$ 5.5$ million, this allows a second stage investment that can cost as much as $\$ 45$ million. Thus, a relatively small drop in the cost of the initial experiment $(8.9-5.5=3.4)$ allows a relatively large increase in the cost of the project $(45-11=34)$.

An interesting example of this is the recent surge in the startups looking to commercialize nuclear energy technologies. Recent advances have lowered the costs associated with 
simulating the inside of a nuclear reactor to learn about the viability of a potential new nuclear technology. This, in turn, makes it possible to finance an initial exploration of radical new ideas in nuclear startups, despite the extremely large financial commitments required to build a nuclear reactor (e.g., it takes up to $\$ 4$ billion to build a test reactor). In fact, Bill Gates, who made an investment to enable an initial exploration into the viability of nuclear startup Terrapower, specifically points to advances in supercomputing as the reason behind a resurgence in startups engaged in nuclear energy innovations in the last few years.

The pace of technological progress therefore has a feedback effect on new innovations. Advances in supercomputers or cloud computing affect the cost of experimentation in completely different sectors like nuclear energy and consumer internet and make viable projects that could not have been started in the past. This helps sustain and potentially increase high rates of technological progress.

However, to the extent that risk capital is in short supply, the relative fall in the cost of experimentation can have important consequences for the composition of innovation that is financed by the private sector. The majority of capital in professionally managed venture capital firms comes from endowments, pension funds and sovereign wealth funds. These institutions tend to allocate capital to venture capital investors based on metrics that are often unrelated to investment opportunities (Sampsa Samila and Olav Sorenson (2011)). Capital available to take experimental risks and fund new innovations is therefore limited, particularly in the short run. Thus, investors need to choose which, among many potential profitable ideas, they want to fund. A fall in the cost of experimentation in some areas will increase the value of investing in those areas relative to others. Capital will then flow from areas with more costly experiments to those with less costly experiments. This will slow the innovation in the areas with less capital and possibly increase the shift in capital to the area with ever cheeper experiments. This idea may provide an explanation for the 
relative dearth of capital is some areas of our economy such as biotech and greentech where technological advancement seems so important, while technologies related to mobile apps and social web seem to find abundant capital.

The greater proportion of startups being financed by less expensive experiments also leads to changes in the type of financier that fund new ventures. When ventures require millions and even tens of millions of dollars to start they typically need to be backed by investors with large pools of capital. When the costs of experimentation plummet there are a larger number of less expensive experiments that need to be run. This fall in the cost of experimentation should mean that investors with much smaller pools of capital can find viable investment opportunities. The last decade has seen a dramatic rise in angel networks, super-angel funds, accelerators and incubators as well as crowd funding. Furthermore, a new style of investing has risen that is colloquially referred to as 'spray and pray' in which investors take a very large number of small bets with limited due diligence and hope that just one or two of these experiments turn out to be extremely successful. Each of these different types of investors and investing styles is the natural consequence of the dramatic fall in the costs of starting a new high technology firm. In an economy with a plethora of very small start up experiments that need to be run, investors naturally arise to support them. These 'financial innovations' help to maximize the impact of the technological shocks to the cost of experimentation.

To summarize this section, we emphasize three points related to the cost of experimentation. First, differences across industries in the costs of experimentation and the ability to learn from experimentation have a bearing on the degree of experimentation and radical innovation. For example, the very long time frames and costs associated with learning about a new way to produce clean energy or different approaches to curing cancer create a dearth of experimentation, despite intense societal interest (Jose-Maria Fernandez, Roger M. Stein and Andrew W. Lo, 2012; David E. Fagnan, Jose-Maria Fernandez, 
Andrew W. Lo and Roger M. Stein, 2013).

Second, the pace of technological progress has a feedback effect on new innovations. As technological advances such as supercomputers or cloud computing diffuse, they have an effect on the cost of experimentation. The advances make viable projects that had a negative expected value in the past. However, the falling cost of experimentation will also pull financiers towards the sectors where the returns from experimentation are greatest. Sectors where experiments are expensive or not as discriminating in the early stages of a venture are less attractive to investors and less likely to receive attention from financiers, independent of their importance for society or the amount of ideas that are available to be commercialized.

Third, financial markets will naturally respond to the fall in the costs of experimentation. New smaller investors and even individuals can more readily participate in a market with low cost experiments. Note, however, that this market will be rife with failure. Many will quickly conclude that this is because more junk is being funded by these smaller unsophisticated investors. However, more experimental projects should be expected to fail at a higher rate. Thus, failure rates alone will not reveal whether investors are making more investments or just investing in more radical projects. Instead we must wait to see the extent to which new radical innovations that change how we live emerge from this cacophony of experimentation. From the perspective of investors, it is important to note that most investors in startup ventures will lose their investments entirely, while only a few will back startups that end up becoming big hits. This is even more likely to be true when the falling cost of experiments make 'long shot bets' viable for a first financing. The profile of returns from such investments looks very similar to a lottery, suggesting that transparency into the likely outcomes of investments will be helpful for the larger set of individuals getting access to equity investments in private ventures through reforms such as the JOBS Act - that aim to provide unaccredited individuals access to such investments. 


\section{Financing Risk}

Having examined how the direct cost of experimentation can impact the composition of entrepreneurship and innovation, we turn next to challenges associated with the act of staged financing. We first look at a how staging investments can impose a challenge even when intermediate information from the experiment is positive.

Financing available for startups engaged in innovation is notoriously volatile (Gompers and Lerner, 2004; Steven Kaplan and Antoinette Schoar, 2005; Paul Gompers, Anna Kovner, Josh Lerner and David Scharfstein, 2008). Entrepreneurs and venture capital investors constantly worry about these fluxes in capital and refer to them as financing risk: the risk that the survival of an otherwise healthy startup might be threatened by a negative shock to the supply of capital in its sector when it is looking for the next round of funding and hence derail its progress. ${ }^{6}$ This worry seems rational given the ebbs and flows of capital that have occurred within different venture sectors at different times.

Ramana Nanda and Matthew Rhodes-Kropf (2014) explicitly model the response to financing risk by venture capital investors and provide a theoretical framework for why investors' response impacts the most novel technologies in the economy. They show that investors can respond to financing risk by providing firms more upfront funding, hence making startups less vulnerable to the future state of the capital markets. The investor response can effectively eliminate financing risk, but it also comes at a cost: providing firms greater upfront funding reduces investors' ability to abandon their investment in startups if intermediate information on its prospects is poor. In fact, the value of the lost real option can be high enough that it makes the investment unviable. They show how this tradeoff between wanting to protect firms from financing risk and wanting to preserve the option to abandon the investment is most salient for firms engaged in radical innovations.

\footnotetext{
${ }^{6}$ Large firms who finance with debt and face a similar risk refereed to as rollover risk when trying to issue new bonds to replace maturing bonds (Viral Acharya, Douglas Gale and Tanju Yorulmazer, 2011; Zhiguo He and Wei Xiong, 2012b,a).
} 
Their model therefore predicts that the startups most susceptible to financing risk are the ones commercializing radical innovations. These are the ventures that are most likely to be funded when financing risk is low and most likely to be constrained when financing risk is high.

The insight from Nanda and Rhodes-Kropf (2014) can be seen in the context of our model by noting that financing risk reduces the probability that a firm will receive the next round of funding and hence is equivalent to a less informative experiment. That is, it reduces the value of experimentation. Hence, the types of startups that are funded when financing risk is high are safer, less novel ones. This fits the intuition that good, solid firms are funded when capital is not freely available. The results also suggest, however, that investors are more willing to experiment in boom times, so that these are times when more novel, experimental startups are financed. Startups funded in boom times should be more likely to fail (when investors exercise their abandonment options), but also likely to have bigger successes. Many take the fact that failure rates among venture backed companies are higher during boom times as evidence of lower quality investments, driven by a fall in investor discipline. Nanda and Rhodes-Kropf (2014) note, however, that times of greater experimentation would also be associated with increased failure rates. What distinguishes novel startups from worse investments is that the few that succeeded are more likely to be transformational.

Figure 1 from Ramana Nanda and Matthew Rhodes-Kropf (2013) (here reproduced as figure 2) provides intuition for the idea. The image on the right of figure 2 shows the standard expectation of what occurs during a boom - the distribution of expected investment payoffs essentially 'shifts' left (from the dashed line to the solid line) resulting in more failures and lower expected payoffs. The image on the left of figure 2 depicts the alternative in which more experimental projects are completed in hot markets. As can be seen, the failure rate also increases in this instance but extreme success also become more 
Ex ante risky investments

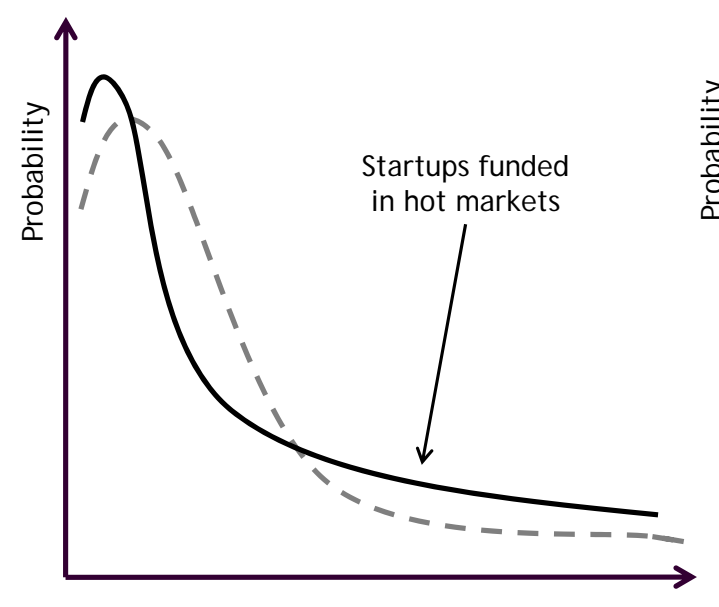

Ex post Payoff
Ex ante worse investments

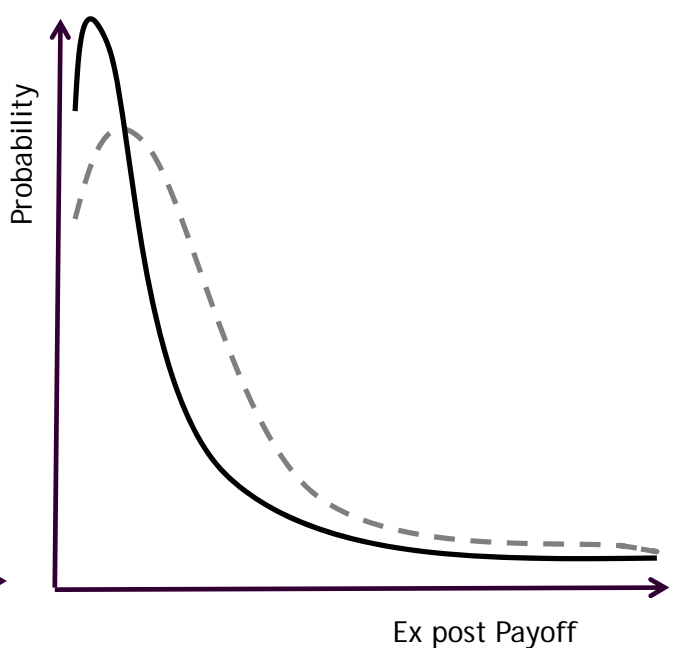

Figure 2. Distinguishing Risky investments from worse investments. The figure depicts the ex post DISTRIBUTION OF OUTCOMES FOR INVESTMENTS THAT ARE RISKIER VERSUS WORSE EX ANTE.

likely. While the expected value of investments in hot markets may be lower, higher, or the same, what should differ is that the outcomes will be more in the tails of the distribution - higher failure rates and more extreme successes.

Nanda and Rhodes-Kropf (2013) examine startups whose initial investment from VCs occurred between 1984 and 2004, and study how the financing landscape when the startup was initially funded related to its ultimate outcome. They find, consistent with conventional wisdom, that startups funded in 'hot' markets were more likely to fail. However, conditional on an IPO, firms financed in more active times had higher valuations when they went public, controlling for the level of the stock market on the day of their IPO. Among firms that had an IPO, those funded in hot markets also filed more patents and their patents were more highly cited. This suggest that firms funded in hot markets were more risky, novel investments that were more likely to fail but conditional on success were more innovative.

Nanda and Rhodes-Kropf (2013) find that this difference does not stem purely from the 
types of investors who are active in hot or cold markets; the same investors, including the most experienced investors, change their investments towards novel technologies at times when financing risk is low. Furthermore, the authors show that this change is not just driven by a response to the arrival of new technologies. Looking at the aspect of hot markets that are exogenous to the arrival of new technologies, they find that increases in the availability of capital play a causal role in funding novel technologies, consistent with the notion that investors are more willing to experiment with an initial funding of such firms at times when financing risk is low. This is a different way to think about investment cycles in venture capital, as it shows that cycles in the financial markets can amplify and even drive innovation in the 'real economy'.

Research on financing risk for startups has also focused on how investors and startups can overcome the challenges associated with boom and bust cycles in the availability of finance. Incumbent firms that acquire promising startups can play an important role in reducing financing risk. Vibrant competition among incumbents for the underlying technology of startups can allow startups to be acquired by incumbents if there are shocks to the supply of capital, without it being a firesale. This in turn makes it attractive for venture capital investors to fund an initial exploration into startups, knowing that if intermediate information is positive, there will be a way to finance the technology even if there is a shock to the supply of capital. Furthermore, a vibrant market for ideas, where the startup is able to license or sell their technology in the event that it is doing well is critical to reducing financing risk (Gans, Hsu and Stern 2001). From a policy perspective, it also seems important to distinguish between bubbles in asset prices and bubbles of activity around the introduction of new technologies (William H. Janeway (2012)). Anecdotally, financial market activity has been linked to revolutionary new technologies, but is usually seen as a response to, rather than a driver of, radical new technologies. This work suggests that in fact financial market activity can lead to more innovation, making it important 
not to diffuse bubbles of activity in technology investing. This work suggests that some extremely novel but capital intensive technologies may in fact need 'hot' financial markets to get through the initial period of diffusion because otherwise the financing risk for them is too extreme.

\section{Failure Tolerance}

Having discussed constraints to experimentation when intermediate information is positive, we now turn to costs and constraints related to experimentation that arise when intermediate information is negative.

From an investor's perspective, the benefit of running an experiment stems from an ability to abandon the investment if intermediate information is poor. However, this means that an entrepreneur may find themselves rapidly out of work when the startup is shut down. Many entrepreneurs do not like this scenario and look for investors willing to allow them a second go if intermediate information is negative, or even look for investors who are willing to fund the project more fully up front. In fact, in an extreme, entrepreneurs may not be willing to take an investment from investors who have a reputation for exercising their abandonment options. A number of empirical papers consider the impact on innovation of policies that create a tolerance for failure to motivate agents to engage in experimentation (M. Burkart, D. Gromb and F. Panunzi, 1997; Viral Acharya and K. Subramanian, 2009; Gustavo Manso, 2011; Daniel Ferreira, Gustavo Manso and Andre Silva, 2011; Philippe Aghion, John Van Reenen and Luigi Zingales, 2009; Xuan Tian and Tracy Yue Wang, 2014).

Ramana Nanda and Matthew Rhodes-Kropf (2015) note that investors and policy makers cannot set an optimal failure tolerance policy on a project-by-project basis. Instead there are many reasons why a single policy will be fixed in advance and apply to all projects they choose to pursue. For example, any investor in innovation may desire to 
foster a reputation of entrepreneurial friendly. ${ }^{7}$ They may do so by committing not to shut down projects quickly. Alternatively, a company culture or level of bureaucracy will apply to all projects. Or, for example, a government looking to stimulate innovation may pass laws making it harder to fire employees. These levels of 'failure tolerance' will apply to all employees, regardless of the project. Put differently a principal often has an 'innovation strategy' that is set ex ante - one that is a blanket policy that covers all projects in the principal's portfolio. This preset policy, culture or bureaucracy may then affect what projects the principal chooses to pursue. These policies however can have unintended consequences by changing the types of startups investors are willing to back in the first place. That is, investors who commit not to shut down a project when intermediate information is negative will be more likely to startup projects where there is less variance in the expected value following the initial experiment. That is investors who are more failure tolerant will be less likely to back more novel, experimental projects.

More generally, this work implies that formal and informal institutions in an economy can play an important role in the level of innovation through their role in promoting the amount of experimentation that investors undertake. First, certain financial intermediaries are, by design, limited in the amount of experimentation they can engage in. Banks, for example, do not share proportionately in the benefits when a startup does extremely well but do suffer the losses. They are therefore much less likely to invest in startups where the outcomes might vary significantly. Indeed Black and Gilson (2000) argue that bank oriented economies are less likely to encourage startups engaged in innovation. In a similar vein, regulations surrounding the amount of money that can be committed by pension funds to asset classes such as venture capital can have important implications for the amount of capital available to support the financing of experimentation (Samuel

\footnotetext{
${ }^{7}$ For example, the manifesto of the VC firm the Founders Fund (investors in Facebook) reads "companies can be mismanaged, not just by their founders, but by VCs who kick out or overly control founders in an attempt to impose 'adult supervision.' VCs boot roughly half of company founders from the CEO position within three years of investment. Founders Fund has never removed a single founder..." (emphasis added) http://www.foundersfund.com/the-future
} 
Kortum and Josh Lerner (2000)).

Second, policies that are aimed at motivating experimentation by entrepreneurs can limit the degree to which investors are willing to finance this experimentation. For example, lenient bankruptcy laws may encourage entrepreneurs to take on bolder experiments, but at the same time make investors less willing to fund the experimentation since their return if things go badly is reduced (Isin Guler (2007b) Isin Guler (2007a), Nanda and Rhodes-Kropf (2015), Geraldo Cerqueiro, Deepak Hegde, Mara Fabiana Penas and Robert Seamans (2013)). On a similar note, employment protection laws might encourage employees in large companies to engage in more experimentation, but can at the same time limit the attractiveness for venture capital investors, who need to hire and fire employees to effectively engage in experimentation (Ant Bozkaya and William R. Kerr (2014)).

Finally, cultural institutions can have important interactions with the formal institutional environment and with the organizational strategies of investors. Cultures where there is a high stigma of failure are ones where entrepreneurs are less likely to want financing from investors with a reputation for shutting down projects. This can lead investors to pick more failure tolerant strategies, and in doing so, only finance the less experimental startups in the economy.

\section{Conclusion}

Entrepreneurship plays a central role in economic growth, but startups need to access finance to succeed. Much prior research on the financing of startups has focused on frictions that prevent capital from reaching the exante most promising startups. Recent research in entrepreneurial finance complements this work by focusing on another possible source of financing frictions: the fundamental uncertainty facing high-tech startups in their earliest stages, where neither the entrepreneur nor the investor knows about the true potential of the venture without investing to learn about the viability of the idea. In this context 
of extreme uncertainty, multi-stage financing allows investors to learn about a venture's potential over time, without committing the full amount upfront. These real options can be particularly valuable in the context of entrepreneurship because most new ventures fail completely, and only a few go on to become extremely successful.

This paper has shown how constraints to staged-financing reduce the value of these real options and hence influence the degree to which investors can effectively experiment. First we have shown how differences in the costs of experimentation across sectors can strongly influence the startups that profit-seeking investors choose to fund, irrespective of their importance to society. Some projects, where the costs of experimentation are too high to be borne by profit-seeking investors, but where the returns to society are high are therefore better off undertaken in setting such as academia or the government. Indeed, even when the cost of experimentation falls, the relative pace of falling costs across sectors can disproportionately lead private capital into sectors where the returns from experimentation are higher.

Second, we have also shown how the process of staged financing can itself impose certain costs to financiers funding experimentation. Formal regulations and informal cultural institutions that make it harder to abandon investments when intermediate information is bad can lead investors to only finance startups where the value of abandonment options is low. These are startups with safer, less novel innovations with the implication that regions where it is harder to engage in experimentation are likely to see fewer startups engaged in innovation.

Finally, potential shocks to the availability of capital when the firm raises its next round of funding can reduce the value of staged financing. The firms for whom staging is most beneficial are the most novel startups in the economy, which is why startups engaged in innovation are most vulnerable to the state of the financial markets. Indeed, we have shown that cycles in the financial markets can amplify and drive innovation in the real 
economy. In fact, some extremely novel but capital intensive technologies may in fact need hot financial markets to get through the initial period of diffusion because otherwise the financing risk for them is too extreme.

Overall, these insights also suggest caution in trying to prevent failure of startup ventures. Failure is a natural part of the experimental process, and in fact, extreme failure and extreme success may be two sides of the same coin. This fact is particularly important to understand in the context of recent regulation allowing crowd-funding and the external environment that has seen a dramatic fall in the cost of early experiments. Our framework highlights that startups that become viable investments when the cost of experimentation falls are likely to be more "long shot bets". While democratizing access to private equity investment is important, policy makers should note that the investments made by crowds of investors are going to be more likely to fail - precisely because these are the marginal "long shot bets" that have become viable investments with the falling cost of experimentation. It seems important that crowds of individuals making angel investments in early stage startups are given the information that helps them understand their odds of success and the implications it has for their investment portfolios.

\section{Appendix}

In this section, we provide a more formal description of the framework outlined in the text. Consider the following investment: A startup requires $\$ X$ to commercialize its technology that may or may not work. With a probability $p$ it will be successful and worth $V$ while with probability $1-p$ it will be worth nothing. The expected value of the project is $p V-X$. Thus this project will not be financed if $X>p V$.

Instead, imagine that the entrepreneur can conduct an experiment before fully funding the startup. This might entail the building of a prototype, a market validation, or an FDA regulated Phase I trial of a new drug. The likelihood that the experiment generates positive intermediate information is $p_{E}$, while the likelihood of intermediate information being negative is $\left(1-p_{E}\right)$. If results from the experiment look promising (the Good outcome), the chance of ultimate success is $p_{G}$, while if the results from the experiment are not promising (the Bad outcome), the chance of success is $p_{B}$. The experiment costs $\$ Y$ to 


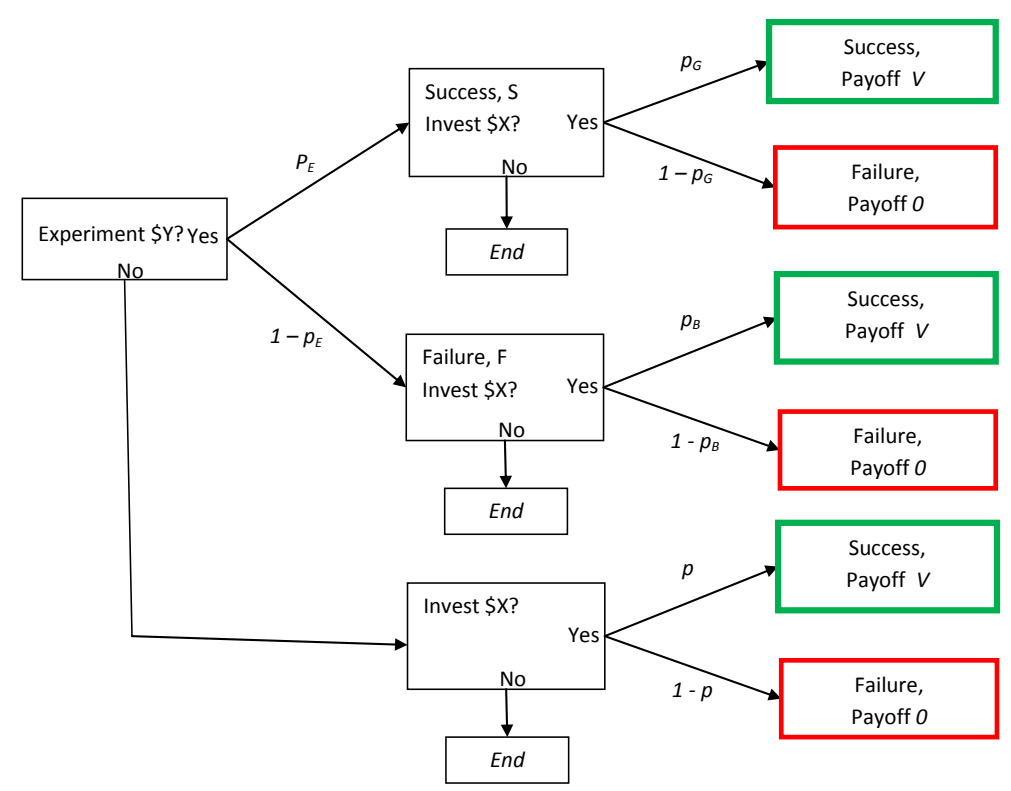

Figure 3. Investor's Decision Tree

run. To be equivalent to the project when no experiment is run $p_{G} * p_{E}+p_{B} *\left(1-p_{E}\right)=p$, i.e., the probability of success is the same whether or not the experiment is run. Thus, the experiment reveals information about the quality of the project. The experiment is valuable anytime that:

$$
p * V-X<p_{E} *\left(p_{G} * V-X\right)+\left(1-p_{E}\right) \operatorname{Max}\left[p_{B} * V-X, 0\right]-Y
$$

i.e. when the expected value without the experiment is less than the expected value with the experiment. When is this true? This cannot hold, for example, for any project that has a positive expected value even after the experiment fails. In this case $\operatorname{Max}\left[p_{B} * V-X, 0\right]=$ $p_{B} * V-X$. Since $p_{G} * p_{E}+p_{B} *\left(1-p_{E}\right)=p$ we see that $p_{E} *\left(p_{G} * V-X\right)+\left(1-p_{E}\right)\left(p_{B} *\right.$ $V-X)=p * V-X$ and running the experiment really is just a waste of resources. This is because it changes no decision as the investor invests $\$ X$ no matter what the experiment reveals. However, if $p_{B} * V-X<0$ then the investor would like to avoid investing when the true probability of success is $p_{B}$. The investor would therefore be willing to pay to learn whether the probability is $p_{G}$ or $p_{B}$. How much the investor is willing to pay depends on how much the investor learns from the experiment.

In an extreme, an experiment might demonstrate nothing, i.e., $V * p_{G}=V * p_{B}$. That is, the probability of earning $\mathrm{V}$ is the same no matter the experiment's outcome. Alter- 
natively, the experiment might provide a great deal of information. In this case $V * p_{G}$ would be much larger than $V * p_{B}$. We can think, therefore, of $V * p_{G}-V * p_{B}$ as the amount or quality of the information revealed by the experiment. $V * p_{G}-V * p_{B}$ is larger if the experiment revealed more about what might happen in the future. ${ }^{8}$ Note that the experiment is not more or less important if the project is riskier - a risker project might be one with a larger $V$ and smaller probabilities of success, $p_{G}$ and $p_{B}$ - but the information revealed by the experiment, $V * p_{G}-V * p_{B}$, could be the same. Thus a project with valuable experiment and the risk of the project are related but not the same. Overall, we see that experimentation is very valuable in situations when relatively small dollars invested can reveal information that results either in a valuable project going forward or preventing a mistaken investment.

We can use equation (1) to see what lowering the cost of experimentation allows from the perspective of investors. An experiment is valuable if the expected payoff from the experiment is both greater than zero and greater than the expected payoff without the experiment -

$$
p * V-X<p_{E} *\left(p_{G} * V-X\right)-Y>0
$$

Thus, if $Y$ falls then some projects that would not have been done (projects such that $p * V-X<0$ and $\left.p_{E} *\left(p_{G} * V-X\right)-Y<0\right)$ can now be run. These are projects with small probabilities of success $(p)$ but where the value of the abandonment option is high $\left(V * p_{G}-V * p_{B}\right.$ is large). Put differently, a lower cost of experimentation is particularly valuable for startups with low chances of success but where an investor can learn a significant amount from an initial experiment.

This framework can also be used to understand the costs and constraints to staged financing. The insight from Nanda and Rhodes-Kropf (2014), that financing risk leads to less innovative startups being funded, can be seen in the context of our model by noting that financing risk reduces the probability that a firm will receive the next round of funding and hence is equivalent making the first stage of the experiment less informative. That is, it reduces the value of experimentation. Hence, the types of startups that are funded when financing risk is high are safer, less novel ones.

Including a cost of early failure for the entrepreneur if intermediate information is negative reduces the value of experimentation for investors, even though they do not directly pay the failure costs. This is because the financier and entrepreneur must negotiate over

\footnotetext{
${ }^{8}$ Note that we can think of $p_{G}$ and $p_{B}$ as posterior probabilities with a prior of $p$. Thus, one special case are martingale beliefs with prior expected probability $p$ and updating follows Bayes Rule. In this case projects with weaker priors would have more valuable experiments.
} 
any surplus generated by the project. The loss from early failure lowers the entrepreneur's expected payoff. If the total expected value of the project does not generate enough to cover the costs borne by both the entrepreneur and investor then the entrepreneur and investor will not be able to find a deal that will induce them to both participate. The deals where they do agree will be ones that will tend to be less innovative, so that by committing to be failure tolerant, investors will shift the projects they fund away from the most innovative projects in the economy. 


\section{REFERENCES}

Acharya, Viral, and K. Subramanian. 2009. "Bankruptcy Codes and Innovation." Review of Financial Studies, 22: 4949 - 4988.

Acharya, Viral, Douglas Gale, and Tanju Yorulmazer. 2011. "Rollover risk and market freezes." Journal of Finance, 66: 11771209.

Aghion, Philippe, John Van Reenen, and Luigi Zingales. 2009. "Innovation and Institutional Ownership." Harvard University working paper.

Bergemann, Dirk, and Ulrich Hege. 2005. "The Financing of Innovation: Learning and Stopping." RAND Journal of Economics, 36: 719-752.

Bergemann, Dirk, Ulrich Hege, and Liang Peng. 2008. "Venture Capital and Sequential Investments." Working Paper.

Bozkaya, Ant, and William R. Kerr. 2014. "Labor Regulations and European Venture Capital." Journal of Economics and Management Strategy, 23: 776-810.

Burkart, M., D. Gromb, and F. Panunzi. 1997. "Large Shareholders, Monitoring, and the Value of the Firm." Quarterly Journal of Economics, 112: 693 - 728.

Cerqueiro, Geraldo, Deepak Hegde, Mara Fabiana Penas, and Robert Seamans. 2013. "Debtor Rights, Credit Supply, and Innovation." SSRN Working Paper 2246982.

Cornelli, Franchesca, and O. Yosha. 2003. "Stage Financing and the Role of Convertible Securities." Review of Economic Studies, 70: 1-32.

Ewens, Michael, Ramana Nanda, and Matthew Rhodes-Kropf. 2015. "Entrepreneurship and the Cost of Experimentation." Harvard Business School Working paper no. 15-070.

Fagnan, David E., Jose-Maria Fernandez, Andrew W. Lo, and Roger M. Stein. 2013. "Can Financial Engineering Cure Cancer?" American Economic Review: Papers and Proccedings, 103(3): 406-411.

Fernandez, Jose-Maria, Roger M. Stein, and Andrew W. Lo. 2012. "Commercializing Biomedical Research Through Securitization Techniques." Nature Biotechnology, 30: 395-400. 
Ferreira, Daniel, Gustavo Manso, and Andre Silva. 2011. "Incentives to Innovate and The Decision to Go Public or Private." London School of Economics working paper.

Fluck, Z., K Garrison, and S. Myers. 2007. "Venture Capital Contracting: Staged Financing and Later-Stage Syndication of Venture Capital Investments." MIT Working paper.

Gompers, Paul. 1995. "Optimal Investment, Monitoring, and the Staging of Venture Capital." Journal of Finance, 50: 1461-1489.

Gompers, Paul, and Josh Lerner. 2004. The Venture Capital Cycle. Cambridge, MA and London:MIT Press.

Gompers, Paul, Anna Kovner, Josh Lerner, and David Scharfstein. 2008. "Venture capital investment cycles: The impact of public markets." Journal of Financial Economics, 87: 1-23.

Guler, Isin. 2007a. "An Empirical Examination of Management of Real Options in the U.S. Venture Capital Industry." Advances in Strategic Management, 24: 485-506.

Guler, Isin. 2007b. "Throwing Good Money After Bad? A Multi-Level Study of Sequential Decision Making in the Venture Capital Industry." Administrative Science Quarterly, 52: 248-285.

Hall, Robert E., and Susan E. Woodward. 2010. "The Burden of the Nondiversifiable Risk of Entrepreneurship." American Economic Review, 100: 1163 - 1194.

Hellmann, Thomas. 1998. "The Allocation of Control Rights in Venture Capital Contracts." RAND Journal of Economics, 29: 57-76.

Hellmann, Thomas, and Manju Puri. 2002. "Venture Capital and the Professionalization of Start-Up Firms: Empirical Evidence." Journal of Finance, 57(1): 169-197.

He, Zhiguo, and Wei Xiong. 2012a. "Dynamic debt runs." Review of Financial Studies, 25(6): 1799-1843.

He, Zhiguo, and Wei Xiong. 2012b. "Rollover Risk and Credit Risk." Journal of Finance, 67(2): 391-429.

Janeway, William H. 2012. Doing Capitalism in the Innovation Economy. Cambridge University Press. 
Kaplan, Steven, and Antoinette Schoar. 2005. "Private Equity Performance: Returns, Persistence and Capital Flows." Journal of Finance, 60(4): 1791-1823.

Kaplan, Steven, Berk Sensoy, and Per Stromberg. 2009. "Should Investors Bet on the Jockey or the Horse? Evidence from the Evolution of Firms from Early Business Plans to Public Companies." Journal of Finance, 64(1): 75 - 115.

Kerr, William, Ramana Nanda, and Matthew Rhodes-Kropf. 2014. "Entrepreneurship as Experimentation." Journal of Economic Perspectives, 28: 25-48.

Kortum, Samuel, and Josh Lerner. 2000. "Assessing the impact of venture capital on innovation." Rand Journal of Economics, 31: 674-92.

Manso, Gustavo. 2011. "Motivating Innovation.” Journal of Finance, 66(5): 1823 1860.

Nanda, Ramana. 2015. "Experimentation and Real Options in Entrepreneurial Financel." Harvard Business School Note 815-056, 1-35.

Nanda, Ramana, and Matthew Rhodes-Kropf. 2013. "Investment Cycles and Startup Innovation." Journal of Financial Economics, 110(2): 403-418.

Nanda, Ramana, and Matthew Rhodes-Kropf. 2014. "Financing Risk and Innovation." Harvard University working paper.

Nanda, Ramana, and Matthew Rhodes-Kropf. 2015. "Innovation Policies." $H B S$ Working Paper.

Ries, Eric. 2011. The Lean Startup: How Today's Entrepreneurs Use Continuous Innovation to Create Radically Successful Businesses. Crown Business Publishing.

Sahlman, William A. 1990. "The Structure and Governance of Venture-Capital Organizations." Journal of Financial Economics, 27: 473-521.

Samila, Sampsa, and Olav Sorenson. 2011. "Venture capital, entrepreneurship and economic growth." Review of Economics and Statistics, 93: 338-349.

Tian, Xuan, and Tracy Yue Wang. 2014. "Tolerance for Failure and Corporate Innovation." Review of Financial Studies, 27(1): 211-255. 